\title{
Heparan Sulfate
}

National Cancer Institute

\section{Source}

National Cancer Institute. Heparan Sulfate. NCI Thesaurus. Code C540.

Heparitin Sulfate. A glycosaminog lycan, structurally similar to heparin but with more Nacetyl groups and fewer $\mathrm{O}$ - and $\mathrm{N}$-sulfate groups. Occurs in the liver, aorta, and lung. Accumulates in several mucopolysaccharidoses. 